\title{
Tricuspid atresia with transposition of the great arteries in adolescents and adults: current state and late complications
}

\author{
CAROLE A WARNES, JANE SOMERVILLE \\ From the Paediatric and Adolescent Unit, National Heart Hospital, London
}

SUMMARY The outcome was reviewed in 17 patients aged 15-40 years with tricuspid atresia and transposed great arteries selected by survival beyond age 14 years. Only five lead normal lives (ability index 1 or 2); the rest are dead or disabled. Arrhythmias occurred in seven. Maintenance of sinus rhythm is important because incessant atrial arrhythmias cause serious symptomatic deterioration. Pulmonary vascular disease and subaortic stenosis were important determinants of late mortality and morbidity. Because the mortality associated with the Fontan operation was high in these patients it should be performed with impeccable surgical technique and only in those who fulfil all the selection criteria for the operation. A shunt is the preferred option when any of the criteria are not met.

Palliative surgery and the Fontan operation have modified the course of tricuspid atresia and transposed great arteries, but little is known about the outcome in adults with this condition. We have reviewed 17 adolescents and adults with this anomaly and have assessed the factors which contributed to their death and disability.

\section{Patients and methods}

We reviewed all patients with angiographically proven tricuspid atresia and transposed great arteries who were seen at the National Heart Hospital, London, since 1965 and who survived beyond age 14 years. The 17 patients (aged 15-40 years) were divided into two groups-group A: 12 patients with palliative shunts or no previous surgery (six are alive to date) and group B: five patients who had a Fontan operation or modification at 15-21 years; only one is alive. The causes of death were analysed and necropsy data were examined when they were available. All living patients were examined in 1986 and had chest $x$ ray, electrocardiogram, exercise test by the modified Bruce protocol, and 24 hours of ambu-

\footnotetext{
Requests for reprints to Dr Jane Somerville, Paediatric and AdolesWom Unit, National Heart Hospital, Westmoreland Street, London W1M 8BA.

Accepted for publication 19 February 1987
}

latory electrocardiography. The left ventricular ejection fraction was measured by cross sectional echocardiography and equilibrium electrocardiogram-gated radionuclide angiography. The ability index was determined in each patient to evaluate their quality of life (figure). ${ }^{1}$

\section{Results}

GROUP A: PATIENTS WITH PALLIATIVE SHUNTS OR NO SURGERY

Table 1 shows the data on 12 patients. Nine had pulmonary stenosis. Two (cases 2 and 5) had shunt operations before the age of one, a further five needed surgery during the first decade, and one had a Blalock-Taussig shunt at 17 years. One patient had her first shunt operation at 34 years. Seven patients had Blalock shunts, two a Glenn anastomosis (cases 5 and 9), and three patients had a direct aortopulmonary anastomosis-Potts (case 2), Watërston (case 12), or from ascending aorta to left pulmonary artery (case 5). Three patients without pulmonary stenosis (cases 4,7 , and 11 ) survived more than 14 years without surgery, but had severe pulmonary vascular disease and presented with serious symptoms (haemoptysis, severe hypoxia) in the second and third decades. In a fourth patient (case 5) pulmonary vascular disease only developed after three previous shunt procedures, almost certainly as a 
Ability index

$\begin{array}{ll}\text { Grade } 1 \text { Normal life } \\ & \text { Full time work or school } \\ \text { Can manage pregnancy }\end{array}$

Grade 2 Able to do part time work Life modified by symptoms

Grade 3 Unable to work Noticeable limitation of activities

Grade 4 - Extreme limitation Dependent Almost housebound

Figure Ability index classification.

result of a direct aorto-pulmonary artery shunt performed when she was eight years old.

\section{Mortality}

Six patients aged 15-22 years died-three at operation. One with the Eisenmenger reaction (case 7) had massive haemoptysis from an infarct in the right lung and died after emergency lobectomy. Another with a failing Glenn anastomosis (case 9), small pulmonary arteries, and mild subaortic stenosis died at an attempted Blalock shunt. This was her third operation. The third death occurred in a patient (case 8) with angina, mild aortic valve stenosis, and severe subaortic stenosis; she died in asystole after extensive resection $(>4 \mathrm{~g})$ of muscle from the sub- aortic right ventricle; the ventricular septal defect was large.

Patient 10 died suddenly nine months after an initially successful Blalock shunt performed at the age of 17 years; increasing hypoxia suggested thrombosis of the shunt. A patient (case 12) with an ability index of 2 died from an intracerebral haemorrhage. This was probably caused by habitual glue sniffing; two previous shunts were functioning. Patient 11 died in chronic left ventricular failure with pulmonary vascular disease, mitral regurgitation, and atrial fibrillation.

\section{Survivors: ability index and exercise capacity}

Four of the six survivors lead nearly normal lives (ability index of 1 or 2) (table 1). Two patients with pulmonary vascular disease (cases 4 and 5) are more severely limited (ability indices of 3 and 4).

Six patients performed an exercise test; three of the four with no pulmonary vascular disease reached stage III; one (case 2) stopped in stage II. The two patients with pulmonary vascular disease stopped at stage 0 .

Left ventricular ejection fraction measured by radionuclide angiography ranged from $36 \%$ to $64 \%$ (mean 47). Neither of the two patients with impaired ventricular function (cases 3 and 4) have had previous shunts, but both are hypoxic and have polycythaemia that requires regular venesection. One

Table 1 Clinical data on 12 patients with tricuspid atresia and transposition of the great arteries who had palliative procedures or no surgical treatment

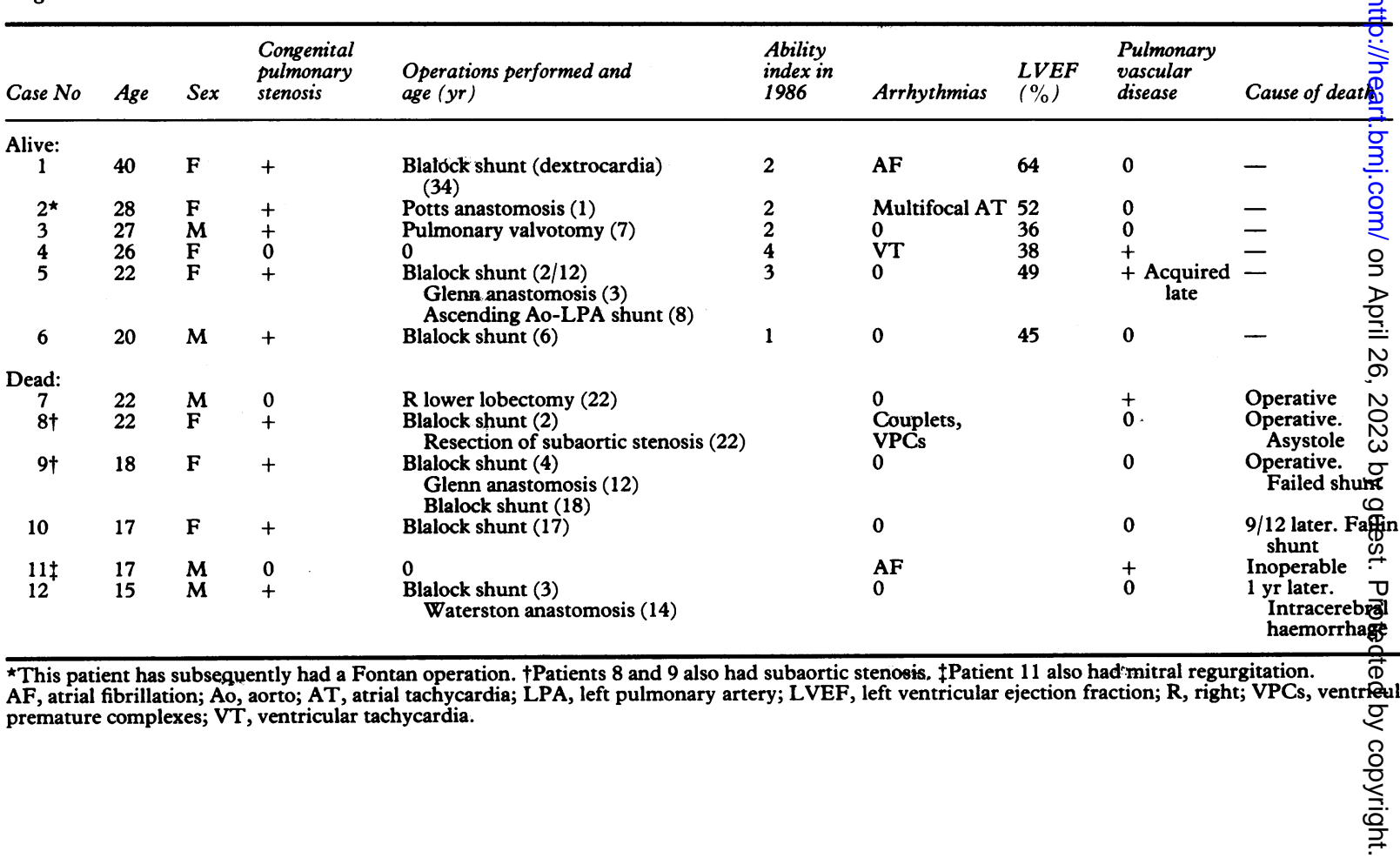


Tricuspid atresia with transposition of the great arteries in adolescents and adults

able 2 Clinical data on five patients with tricuspid atresia and transposition of the great arteries with a Fontan procedure

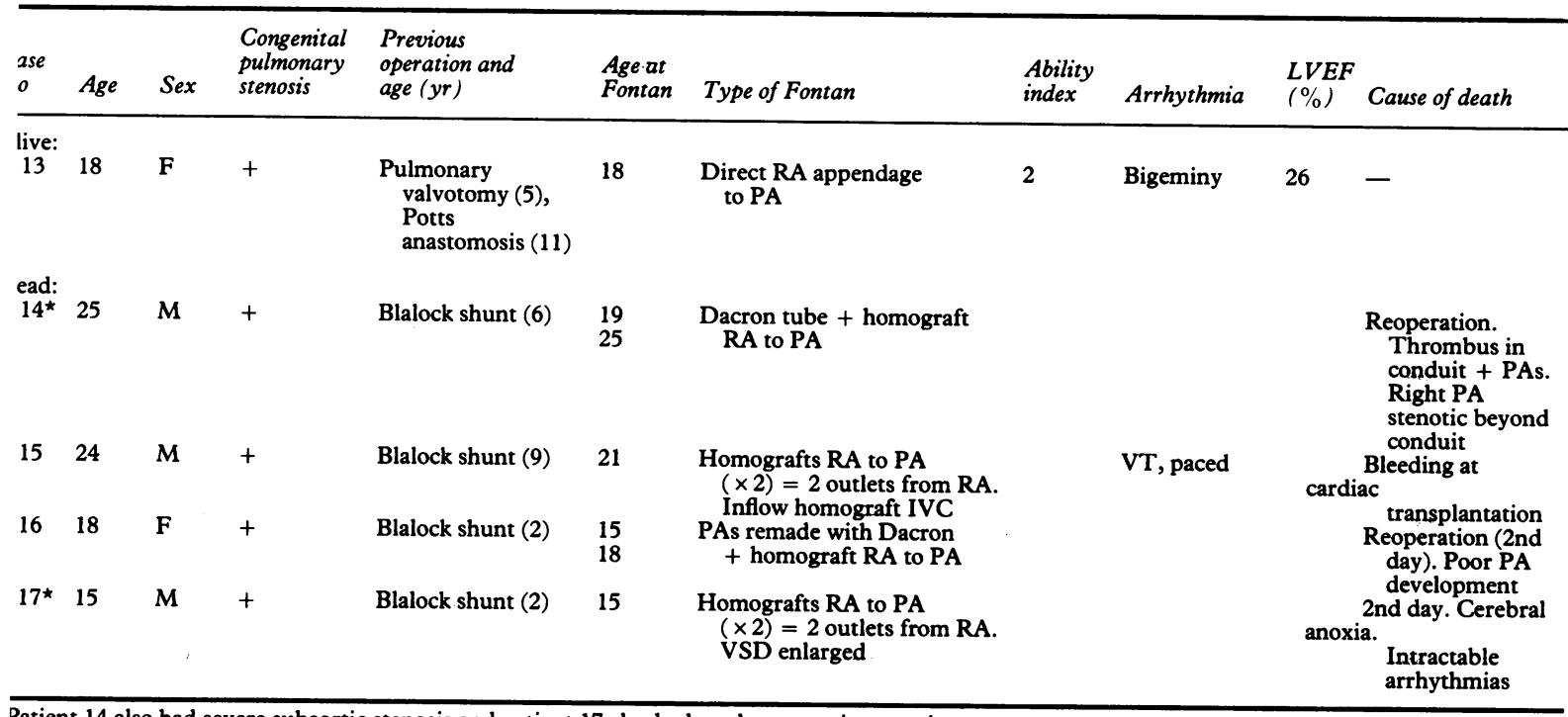

Patient 14 also had severe subaortic stenosis and patient 17 also had moderate aortic stenosis.

JC, inferior vena cava; LVEF, left ventricular ejection fraction; PA, pulmonary artery; RA, right atrium; VT, ventricular tachycardia; VSD, ventricular ptal defect.

(case 4) has pulmonary vascular disease. Despite measurable impairment of ventricular function the other (case 3) has an ability index of 2.

\section{Arrhythmias}

Five of the 12 patients had arrhythmias. Atrial fibrillation caused symptomatic deterioration in two, which improved in one (case 1, who also had a transient stroke) after cardioversion. She has remained in sinus rhythm on quinidine for four years. In three patients asymptomatic arrhythmias were found on Holter monitoring: non-sustained multifocal atrial tachycardia (case 2), non-sustained ventricular tachycardia (case 4), and ventricular couplets $(>30 / \mathrm{h})$ (case 8$)$.

\section{GROUP B: PATIENTS WITH A FONTAN OPERATION}

Table 2 summarises the data on these five patients. All had pulmonary stenosis. Four had had a Blalock shunt in the first decade, and one (case .13) had had a pulmonary valvotomy and a Potts shunt. All patients had improvement in their clinical state after the shunt operation. A Fontan operation, with various modifications, had been performed at 15-21 years (table 2).

\section{Mortality}

There were four deaths, three in patients who were not ideal candidates for the procedure. Three who died at reoperation had not had symptomatic benefit from the Fontan operation. Patient 14, with small pulmonary arteries and severe subaortic stenosis, developed severe right-sided congestion and eventually his conduit and pulmonary arteries became thrombosed. He died at reoperation. Patient 15 had adequate preoperative left ventricular function, but heart block developed at operation and he required an epicardial pacemaker. He was well enough to return to work (ability index 2) but left ventricular function deteriorated. One year after the Fontan operation ventricular tachycardia developed. This was abolished by amiodarone. His ejection fraction fell to $10 \%$ and cardiac transplantation was performed, but he died from uncontrollable bleeding. Patient 16 had poor pulmonary artery development and despite refashioning of the pulmonary arteries with Dacron and a homograft right atrial pressure was high after the Fontan procedure and increased over the next three years. At reoperation the pulmonary arteries were again refashioned but the right atrial pressure remained high $(20 \mathrm{~mm} \mathrm{Hg})$ and she died on the second postoperative day. A 15 year old boy died on the second day after a Fontan operation. Before operation he had moderate subaortic stenosis (gradient $40 \mathrm{~mm} \mathrm{Hg}$ at rest) with a left ventricular end diastolic pressure of $20 \mathrm{~mm} \mathrm{Hg}$ and a pulmonary artery pressure of $34 / 24 \mathrm{~mm} \mathrm{Hg}$.

Survivor: ability index and exercise capacity

One patient (case 13) was alive nine months after the Fontan operation. She had an ability index of 2 , left 
ventricular ejection fraction was $26 \%$, and Holter monitoring showed runs of bigeminy. She reached stage II of the exercise test and was stopped by dyspnoea.

\section{Discussion}

Tricuspid atresia and transposition of the great arteries is uncommon, and without early surgery the prognosis is usually poor ${ }^{2}$ because of hypoxia from low pulmonary blood flow in those with pulmonary stenosis or left ventricular failure in those with high pulmonary blood flow. In this series, however, two patients with pulmonary stenosis survived to 17 and 34 years without surgical treatment, and two paitents with the Eisenmenger reaction survived to 22 and 26 years without surgical intervention. The proportion of patients with this anomaly who survive to adolescence is unknown. The patients we saw were referred to the National Heart Hospital because they had complications and because of our known interest in adult congenital heart disease.

Most patients (16/17 (94\%)) had sufficient pulmonary blood flow to survive the first year without surgery, but $71 \%(12 / 17)$ needed a shunt or pulmonary valvotomy in the first decade. Perhaps those who require surgical treatment in infancy rarely survive to adolescence because they have severe pulmonary stenosis or atresia or a small ventricular septal defect.

Pulmonary vascular disease was common (4/17 patients) and was an important determinant of late mortality and morbidity. In three patients with no pulmonary stenosis (cases 4,7 , and 11 ) the Eisenmenger state developed early; two died before 22 years of age, and the survivor is severely disabled. In one patient (case 5) pulmonary hypertension developed over a decade after an ascending aorta to left pulmonary artery anastomosis had been constructed when she was 8; she now has an ability index of 3 . When left ventricular failure developed in adults with tricuspid atresia, pulmonary congestion rapidly accelerated their deterioration, and they are unlikely to survive to the fourth decade. ${ }^{3}$

The option of cardiopulmonary transplantation is more hazardous in those with previous operations because they are liable to have torrential bleeding from the chest wall during further operation. Many would argue that pulmonary artery banding should be performed in patients with heart failure in infancy to keep the pulmonary vascular resistance low, so that the Fontan procedure, considered by many to be the ultimate operation of choice for this condition, can be performed later. We are not convinced, however, that such patients with a Fontan operation performed at an early age would survive to their early twenties. Also early surgery in such patients virtually rules out subsequent successful cardiopulmonary transplantation. Furthermore, there is no doubt that in infants with heart failure, pulmonary artery banding accelerates the development of subaortic stenosis. ${ }^{4}$ This is why we perform pulmonary artery banding only when failure is uncontrollable or if the chest has to be opened for repair of a coarctation.

Subaortic stenosis is a serious acquired lesion, which when it is severe may cause angina (case 8). It may develop under the aorta in the subaortic "conus" or at the ventricular septal defect. ${ }^{5}$ Those who have subaortic stenosis at birth, or soon after, are unlikely to survive to the second decade. ${ }^{3}$ Four of the patients we describe had subaortic stenosis of varying degrees and two died after attempted relief of the obstruction. We believe that the outlook in patients with subaortic stenosis is poor despite the introduction of new operations. It should be assumed that sympathetic stimuli will increase the gradient. The effect of isoprenaline should be measured at the time of cardiac catheterisation to confirm this. If left ventricular function is sufficiently good we believe that $\beta$ blockade may offer less hazardous short term symptomatic relief of subaortic stenosis than surgery.

Arrhythmias were common (7/17) and occurred irrespective of the type of operation and even when no operation had been performed. Thus arrhythmias appears to be part of the normal course, as they are in tricuspid atresia with normally related great arteries. ${ }^{1}$ Atrial arrhythmias occurred in three patients and ventricular arrhythmias in four. Neither arrhythmia was more common in those with impaired left ventricular function. Incessant atrial fibrillation, however, causes serious symptomatic deterioration and it is important to attempt early cardioversion. Medical treatment has maintained sinus rhythm in all survivors, but left ventricular function must be watched if negative inotropes are used. In one patient complete heart block developed after a Fontan operation at 21 years of age and he needed a pacemaker; the epicardial route was chosen.

Although impairment of left ventricular ejection fraction might be expected in patients with longstanding shunts, all survivors with shunts had normal ejection fractions, but their left ventricular cavities were large. Left ventricular ejection fraction did not correlate with exercise capacity, which was impaired in all patients, but despite this all patients without pulmonary vascular disease led nearly normal lives as judged by the ability index.

Should adolescents and adults with shunts or pulmonary valvotomy be referred for a Fontan oper- 
ation while haemodynamic function is good-that is when they have an ability index of 1 or 2 ? Unfortunately, we cannot answer this question because three of our five patients did not meet the ideal criteria for Fontan; however, the one who was an ideal candidate (case 15) did badly. The mortality of the Fontan operation in those with transposed great arteries is certainly higher than it is in those with simple tricuspid atresia, ${ }^{1}$ and this should be borne in mind when referral of a symptom free adult for this procedure is considered. It could be argued that the patients in this series had their Fontan operations performed relatively late in life and that this may also have adversely affected the outcome. ${ }^{67}$ We do not know whether they would have survived to adulthood if the Fontan operation had been performed earlier. We are not convinced that such patients will live longer or have less disability if they have a Fontan operation. When haemoglobin rises or symptoms become worse in patients who fulfil all the criteria for a Fontan operation they are referred for the operation. We accept that there are greater risks after a Fontan operation and more complications than after a shunt; however, the potential long term benefits may be better. Few patients in this age group will meet all the criteria, mainly because earlier palliative shunts will have been performed too late or will be too large or technically imperfect. Even when only one criterion is not fulfilled the mortality and morbidity of a Fontan operation appear to be unacceptable, and in this circumstance we prefer a shunt, even though they too are associated with added risks and difficulties in these young adults with long term cyanosis. To reduce these difficulties an impeccable surgical technique is required to construct a shunt of ideal size that does not distort the pulmonary arteries or use Dacron, which leads to thromboses. The shunt should be large enough to reduce hypoxia, yet not be too large and overload the left ventricle.
These results are depressing. We recognise that these patients were treated at a time of pioneering surgical efforts and that mistakes were made. This report illustrates the diversity of difficulties encountered in such patients. Even having learnt from our mistakes, we suspect that because of the problems inherent in the anomaly we will still not be able to prevent disabling illness in many adult survivors with tricuspid atresia and transposition of the great arteries.

Carole Warnes was supported by a grant from the British Heart Foundation.

\section{References}

1 Warnes CA, Somerville J. Tricuspid atresia in adolescents and adults: current state and late complications. Br Heart J 1986;56:535-43.

2 Patel R, Fox K, Taylor JFN, Graham GR. Tricuspid atresia. Clinical course in 62 cases (1967-1974). Br Heart $J$ 1978;40:1408-14.

3 Patterson W, Baxley WA, Karp RB, Soto B, Bargeron LL. Tricuspid atresia in adults. Am J Cardiol 1982;49:141-52.

4 Freedom RM, Benson LN, Smallhorn JF, Williams WG, Trusler GA, Rowe RD. Subaortic stenosis, the univentricular heart, and banding of the pulmonary artery: an analysis of the courses of 43 patients with univentricular heart palliated by pulmonary artery banding. Circulation 1986;73:758-64.

5 Somerville J. Congenital heart disease-changes in form and function. Br Heart $J$ 1979;41:1-22.

6 Fontan F, Choussat A, Brom AG, Chauve A, Deville C, Castro-Cels A. Repair of tricuspid atresia. In: Anderson RH, Shinebourne EA, eds. Paediatric cardiology. Edinburgh: Churchill-Livingstone, 1977: 567-80.

7 Sanders SP, Wright GB, Keane JF, Norwood WI, Castaneda AR. Clinical and hemodynamic results of the Fontan operation for tricuspid atresia. Am J Cardiol 1982;49:1733-40. 